\title{
Leproma of the Mouse Foot
}

\author{
C. K. JOB \\ Schieffelin L.eprosy Research Sanatorium-632106, \\ Karigiri, V'ia. Katpadi, Tamil Nadu, S. India. \\ and \\ De'partment of Pathology, Christian Medical College and Hospital, \\ Vellore 632004, Tamil Nadu, S. India. \\ C. J. (j. CHACKO \\ and \\ R. VERGHESE \\ Schieffelin Leprosy Research Sanatorium-6.32106, \\ Karigiri, Via. Katpadi, Tamil Nadu, S. India. \\ and \\ S. PADAM SINGH \\ Department of Radio-Therapy, Christian Medical College and Hospital, \\ Vellore-6.32004, Tamil Nadu, S. India.
}

\begin{abstract}
Leproma of the foot in six T 900r CBA mice produced by local injection with Myco. leprae is reported in this paper. Organisms numbering $10^{4}$ multiplied to the order of $10^{9}$ in 10 to 12 months. The original inoculum of Myco. leprae was obtained from a lepromatous patient and the bacilli were first passaged through a group of $\mathrm{T} 900 \mathrm{r}$ Swiss albino mice and later were subcultured three times successively in T900r CBA mice. One or more of the animals used in each of the subcultures developed erythematous swelling of both inoculated hind feet which on microscopic examination showed typical lepromatous nodules. None of the other 23 strains of bacilli studied from different lepromatous patients showed this reaction. It is possible that this particular strain of Myco. leprae had undergone certain variations producing lesions characteristic of lepromatous leprosy.
\end{abstract}

\section{Introduction}

A limited multiplication of Myco. leprae in the footpads of mice was first reported by Shepard in 1960 (Shepard, 1960). Since then it has been shown by several workers that if 5000 to 10,000 lepra bacilli are injected into the footpads of mice, they will multiply 50 to 100 times in about 6 to 8 months. (Rees, 1964; Job, 1970; Levy et al., 1970). It was also found that larger inoculum failed to give enhanced yields (Rees, 1964). If the same number of organisms are injected into immunologically suppressed mice, a marked enhancement of the growth with a yield ranging from 10,000 to 100,000 times the original number occurred (Rees, 1966; 1967; Shepard and Congdon, 1968; Gaugas, 1967; Job et al., 1974). Histopathological lesions characteristic of lepromatous leprosy has also been described by Rees and his associates in thymectomized irradiated (T 900r) mice 
(Rees et al., 1967; Rees and Weddell, 1968; Rees and Weddell, 1970). Rees has also reported swelling of the hind footpads resembling lepromatous nodules in $5 \%$ of all T 900r mice at risk (Rees, 1971). However no other worker has confirmed the finding of nodular swelling in similarly experimented animals. In this paper we record our finding of nodular leproma of the feet in $6 \mathrm{~T}$ 900r CBA mice.

\section{Material and Methods}

Experiments using T 900r mice belonging to both CBA and Swiss albino strains for culturing $M y c o$. leprae have been going on in our laboratory for over 5 years and the finding of enhanced growth of Myco. leprae in these animals in 7 experiments have been reported elsewhere (Job et al., 1974). In this experiment Myco. leprae obtained from a lepromatous patient with a morphological index (M.I.) of $2 \%$ were injected into both the hind footpads of T 900r Swiss albino mice. The organisms isolated from these Swiss albino mice were subcultured in the footpads of T900r CBA mice successively 3 times. The results of our experience with this strain of $M y c o$. leprae carried through 3 successive generations of T 900r CBA mice is being reported in this paper.

The method used for preparing the inoculum from the tissue of the lepromatous patient, for harvesting the footpads of mice, and for counting the organisms, closely followed that described by Rees in 1964. Both the hind footpads of all the mice were injected with an inoculum containing $10^{4}$ organisms. They were kept in an airconditioned laboratory with a constant environmental temperature of $20-22^{\circ} \mathrm{C}$. At the end of $6,8,10$ and 12 months, one or two of the mice were sacrificed and the tissue from one foot was processed for counting the number of organisms present, and the other foot was amputated, fixed in formalin for $72 \mathrm{~h}$, cut transversely into 3 pieces, decalcified and processed for paraffin sections. Haematoxylin and eosin stain, and acid fast stain were done on $5 \mu \mathrm{m}$ thick sections obtained from all the blocks for histopathological study.

Four of the 6 mice which developed leproma of the feet were autopsied and the internal organs such as lung, liver, kidney, spleen, lymph nodes and heart were examined both grossly and microscopically, using the same histopathological techniques as described above.

\section{Results}

Of the 13, T 900r CBA mice infected with Myco. leprae obtained from T 900r Swiss albino mice, 6 died before 6 months, and only 7 were available for study. Of these, 3 developed erythematous and nodular swelling of both the hind feet resembling human lepromatous nodules (Fig. 1). There was no evidence of external ulceration and the nodules were not warmer than the normal skin of the mice. Smears obtained from them showed numerous macrophages filled with acid fast organisms. The swelling of the feet developed gradually and was noticeable as early as the eighth month. One animal was sacrificed and studied at the tenth month and the other two by the twelfth month. The bacillary counts from one footpad of each of these animals were $5 \times 10^{9} ; 1 \times 10^{9}$ and $3 \times 10^{9}$.

The strain of $M y c o$. leprae obtained from one of these mouse lepromas was subcultured in to $10 \mathrm{~T} 900 \mathrm{r}$ CBA mice. Of these, 5 died within 6 months, and 5 were available for study. One among them developed swelling and nodularity of 


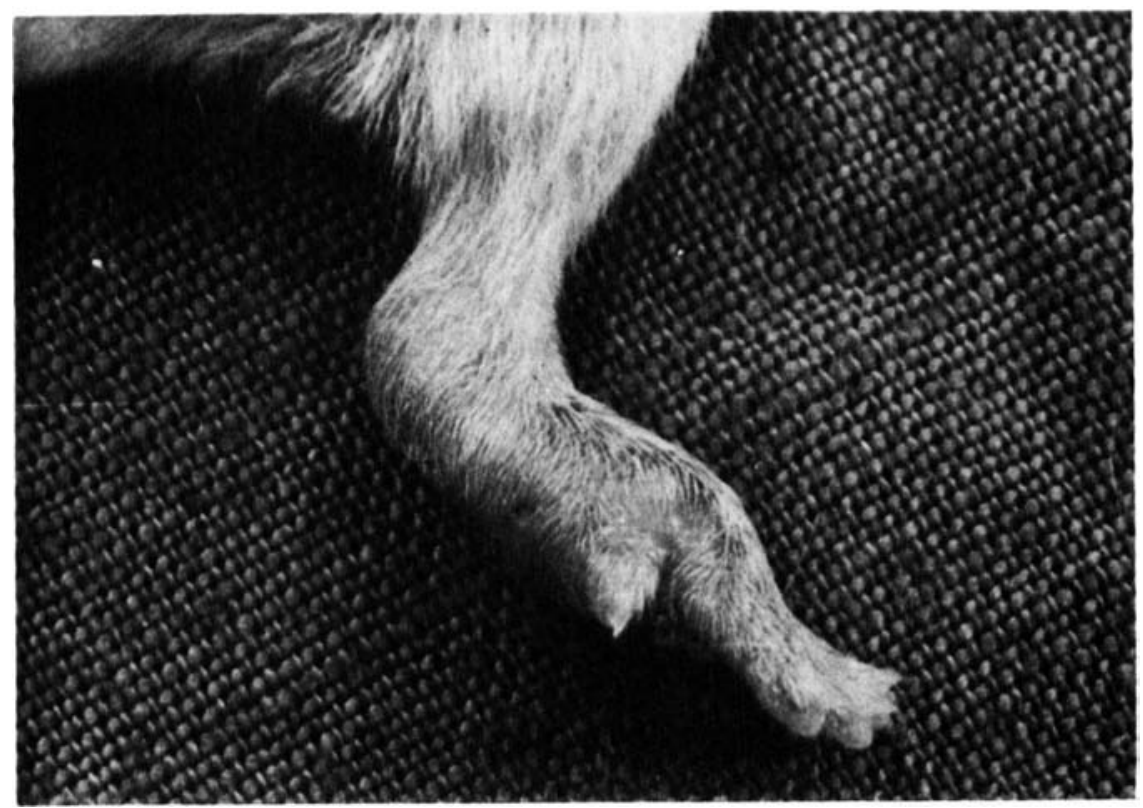

Fig. 1. Photograph of the hind footpad of T 900r CBA mice 10 months after injection with $10^{4}$ Myco. leprae.

the hind feet at the eighth month and was sacrificed at the end of the tenth month giving a yield of $1.4 \times 10^{9}$.

The Myco leprae obtained from one of the mice from the previous group were further subcultured for the third time into $15 \mathrm{~T} 900 \mathrm{r}$ CBA mice. Ten of them died within 6 months, and of the remaining 5, two developed swelling and nodularity of both hind feet beginning from the tenth month and were harvested at the end of the twelfth month giving a yield of $1 \times 10^{9}$ and $3 \times 10^{9}$ organisms. The organisms isolated from this experiment were also subcultured for the fourth time into a group of T 900r CBA mice and the results of this study are awaited.

Microscopic examination of the feet was most interesting. The appearances were almost identical in all the specimens examined from 6 different animals. The lepromatous granuloma involved all the tissues of the foot, namely. the skin, its appendages, subcutaneous fat, tendon, muscle and bone (Fig. 2). The epidermis was atrophic and flattened. The subcutaneous tissue was packed with large macrophages, most of which had a foamy cytoplasm, but some had a granular pink cytoplasm. These macrophage collections were separated from the epidermis by a clear area (Fig. 3), but in focal areas the inflammatory cells reached up to the epidermis (Fig. 4). There were also a few scattered plasma cells and lymphocytes. No polymorphonuclear leucocytes were seen. The striated muscle bundles and tendon tissues were infiltrated and destroyed by the macrophage granuloma (Fig. 5). In some areas the striated muscle fibres were completely replaced by macrophages. The nerves and their perineurium looked normal although surrounded by macrophages (Fig. 6). However, in one instance the nerve was infiltrated by foamy macrophages (Fig. 7). The bones of the foot and bone marrow also showed infiltration by macrophages (Fig. 8). Acid fast stain showed 


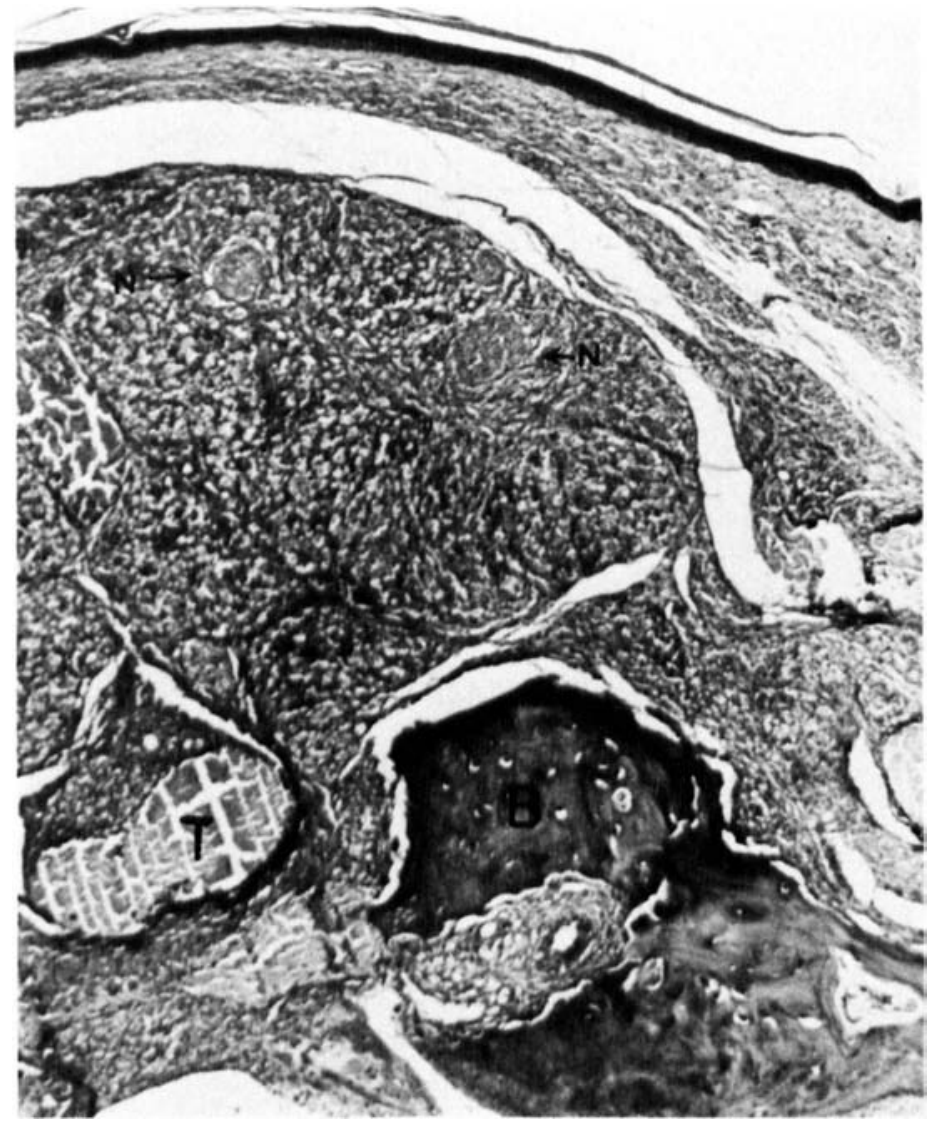

Fig. 2. Low power photomicrograph to show the "leproma" beneath the flat epidermis infiltrating muscle, tendon (T) and bone (B). Note the small cutaneous nerve bundles (N) surrounded by macrophages. (H \& E x 50.)

macrophages packed with Myco. leprae (Fig. 9) in the subcutaneous tissue, tendon, bone and bone marrow. Bacilli were also present in large numbers inside striated muscle cells, but only very rarely inside nerve bundles. The nerve bundle infiltrated with foamy macrophages contained a large number of acid fast bacilli (Fig. 10).

In one animal the macrophage granuloma was, in focal areas, densely infiltrated by lymphocytes (Fig. 11) and Myco. leprae were considerably reduced in number at these sites.

Four of the 6 animals which developed leproma, 2 at the tenth month and 2 at the twelf th month were autopsied, and lung, liver, spleen, kidney, heart and lymph nodes were examined both grossly and microscopically. Gross examination did not reveal any abnormality in any of the organs. On microscopic examination acid fast bacilli were seen in Kupffer cells of the liver and in reticulo-endothelial cells lining the sinusoids of spleen. No granuloma was present in any of the organs in all the animals examined. 


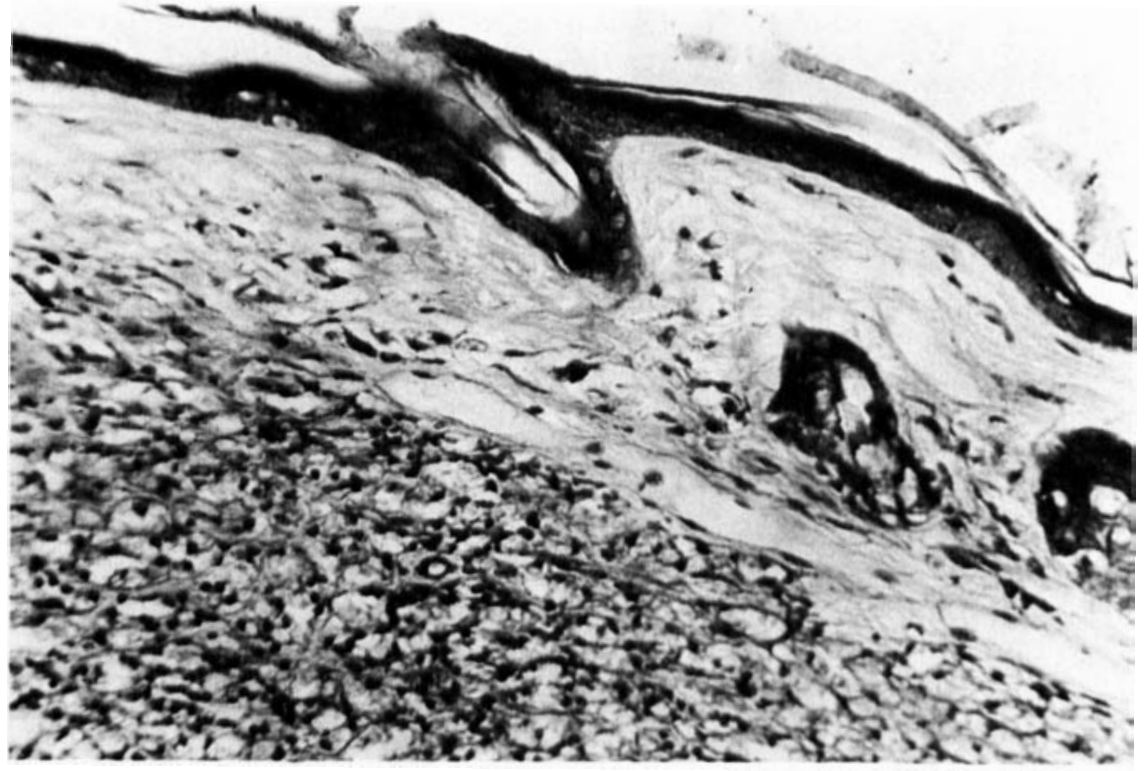

Fig. 3. Microscopic picture of the leproma of the mouse footpad. Note the flattened epidermis, beneath which was seen a clear area separating large collection of foamy macrophages. ( $\mathrm{H} \& \mathrm{E} \times 130$.)

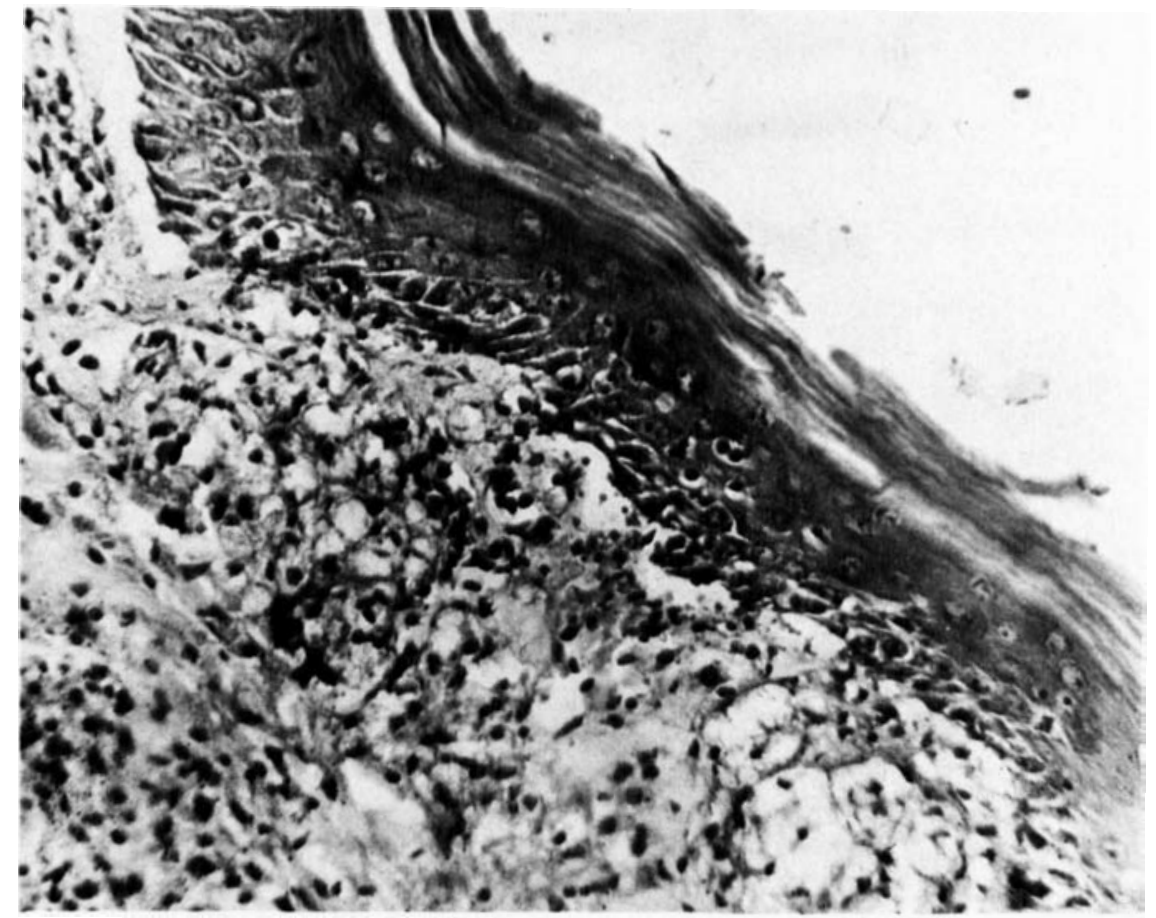

Fig. 4. In focal areas of the lepromatous lesion, the macrophage collections reach up to the epidermis. (H \& E x 500.) 


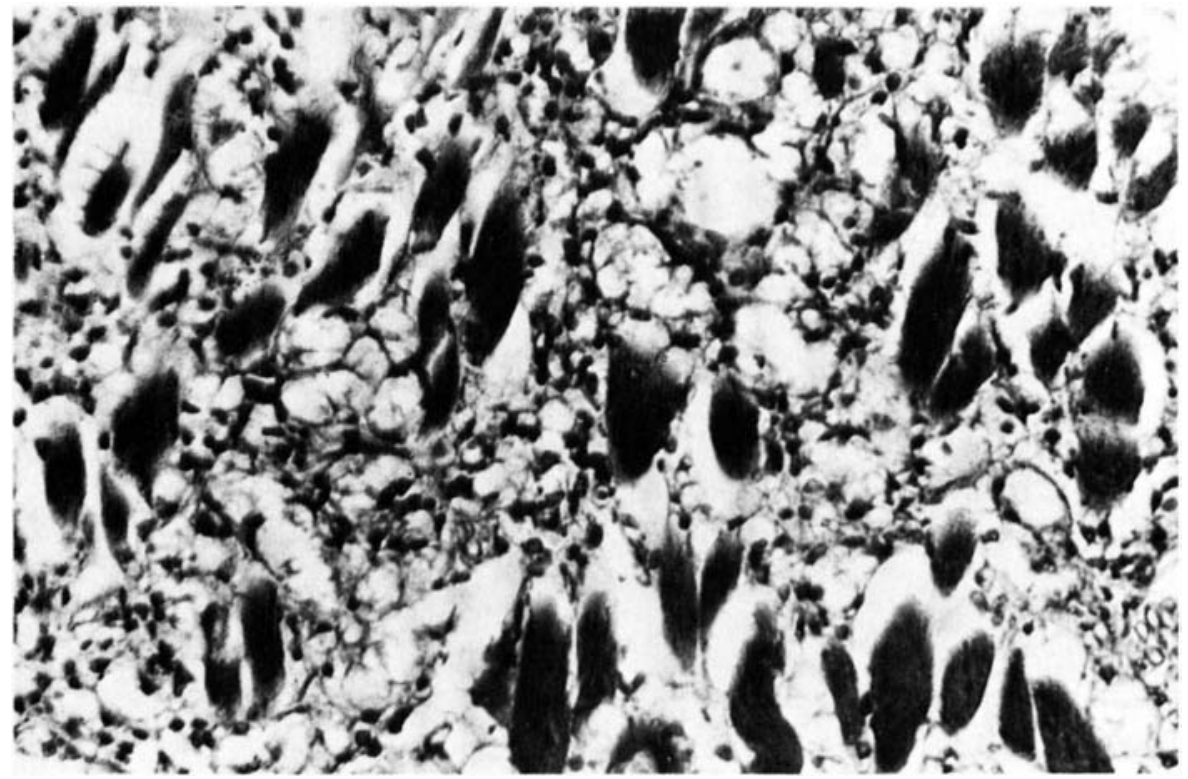

Fig. 5. Foamy macrophages infiltrate the striated muscle cells some of which also underwent foamy change due to the presence of intracellular bacilli (H \& E $\times 500$.)

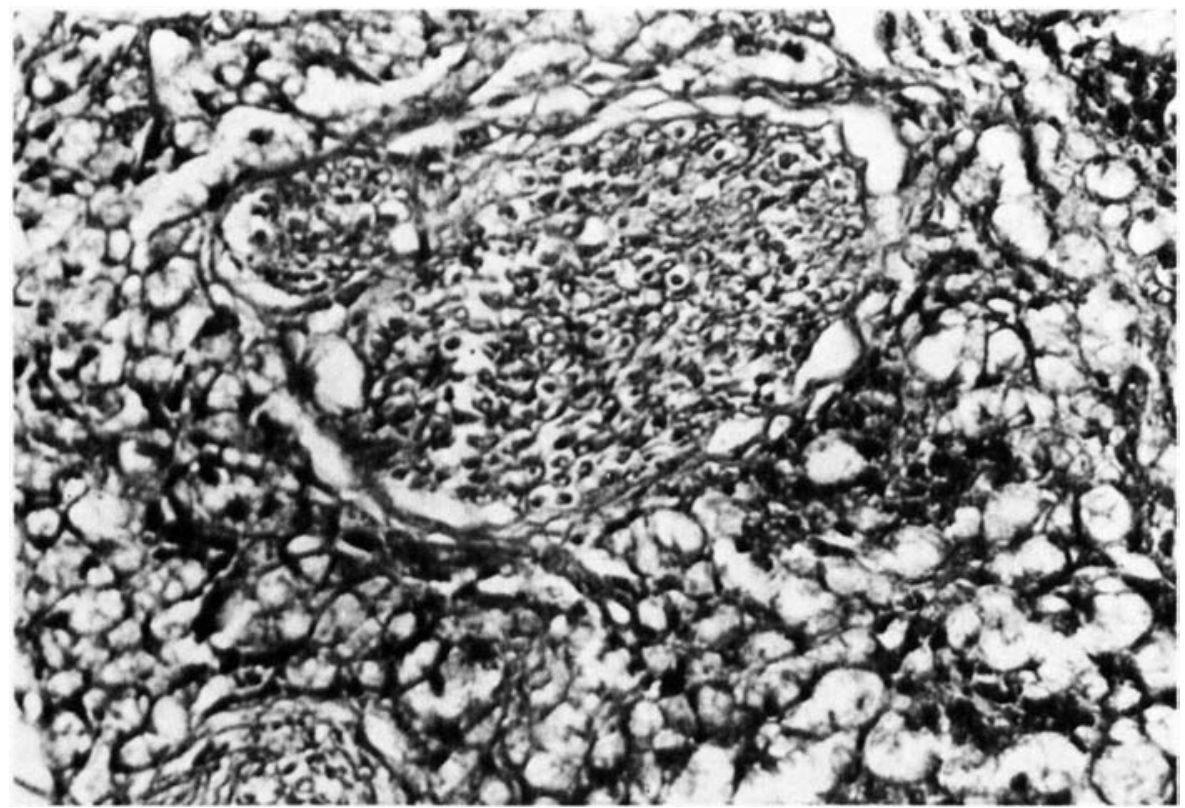

Fig. 6. Apparently normal cutaneous nerve bundles were surrounded by foamy macrophages. (H \& E $\times 500$.) 


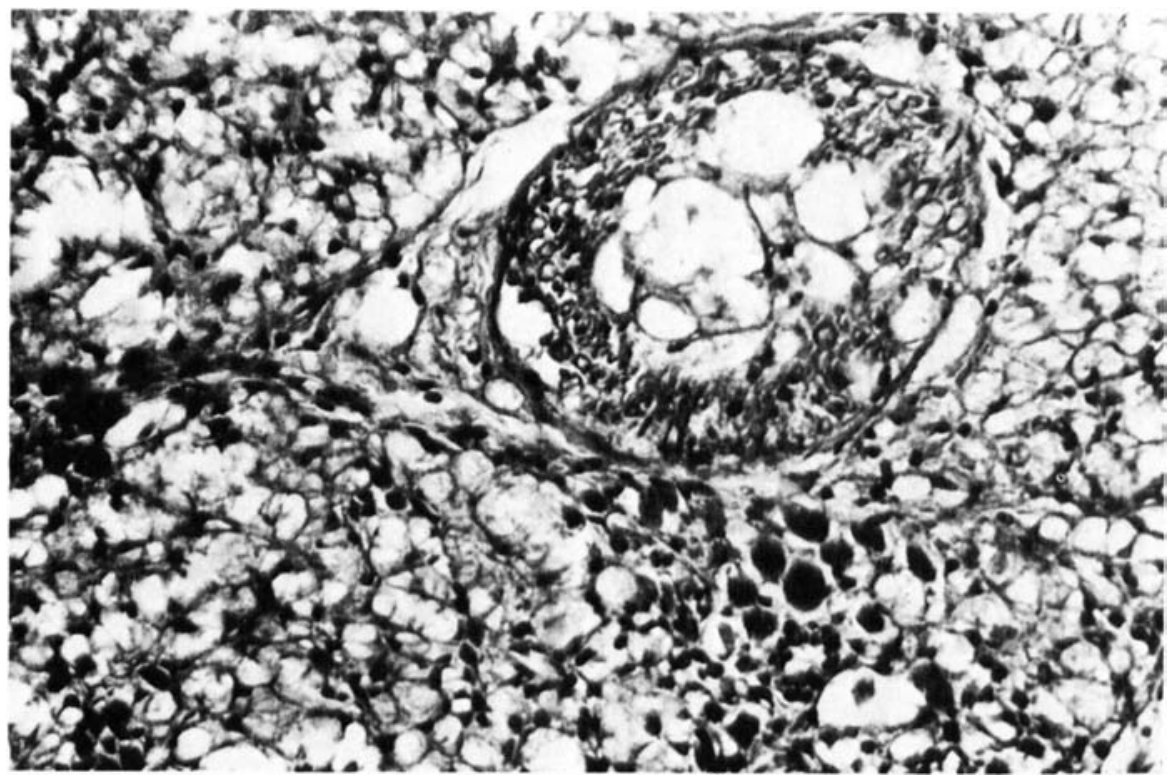

Fig. 7. One nerve bundle was infiltrated with macrophages. Atrophic muscle cells were also seen in the photomicrograph. (H \& E $\times 500$.)

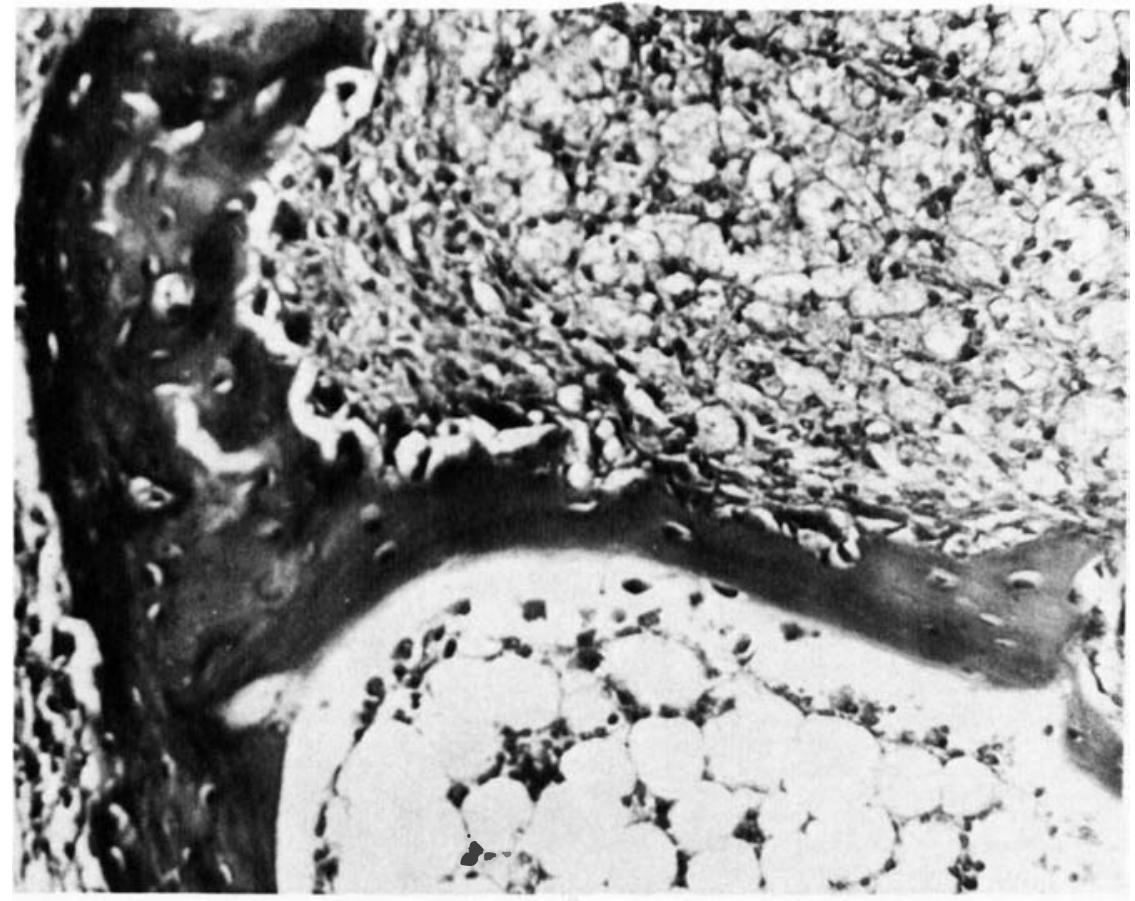

Fig. 8. Bones in the mouse foot were infiltrated with collections of foamy macrophages. Note the normal marrow in the lower part of the photomicrograph. (H \& E.x 500.) 


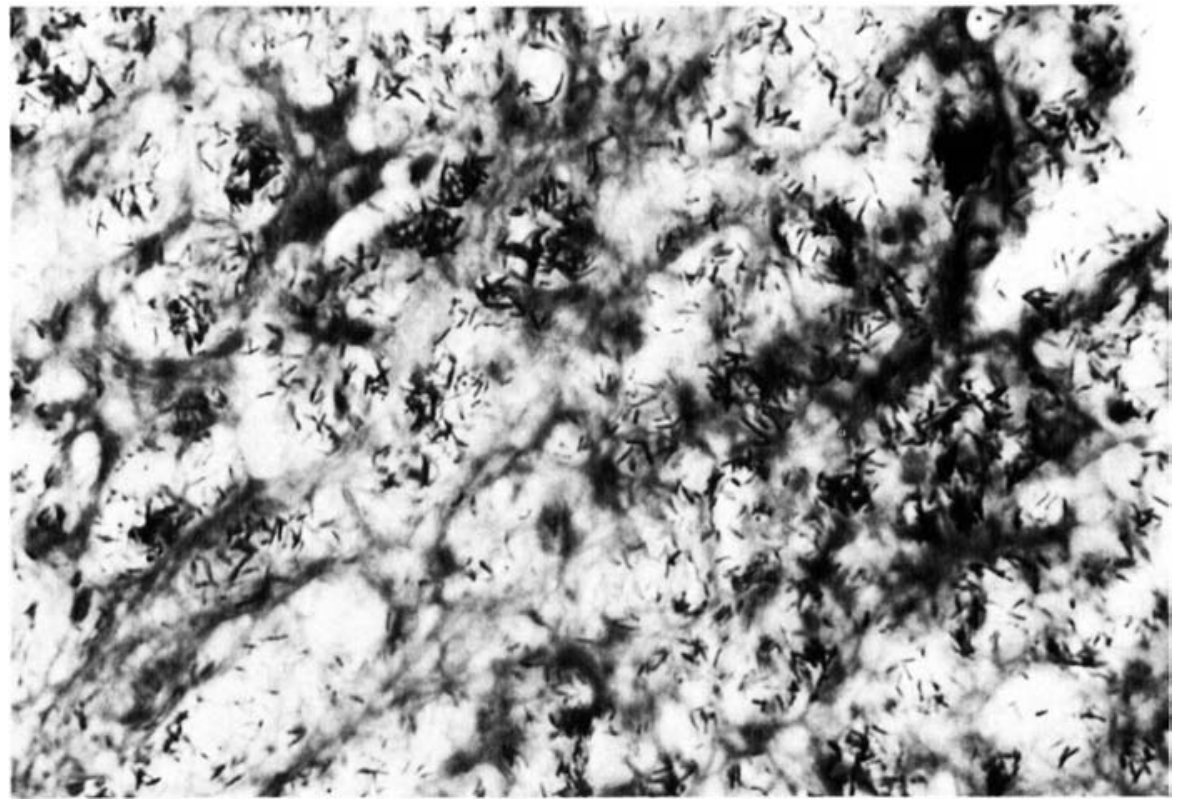

Fig. 9. Foamy macrophages were packed with acid-fast bacilli. (A. F. x 1300.)

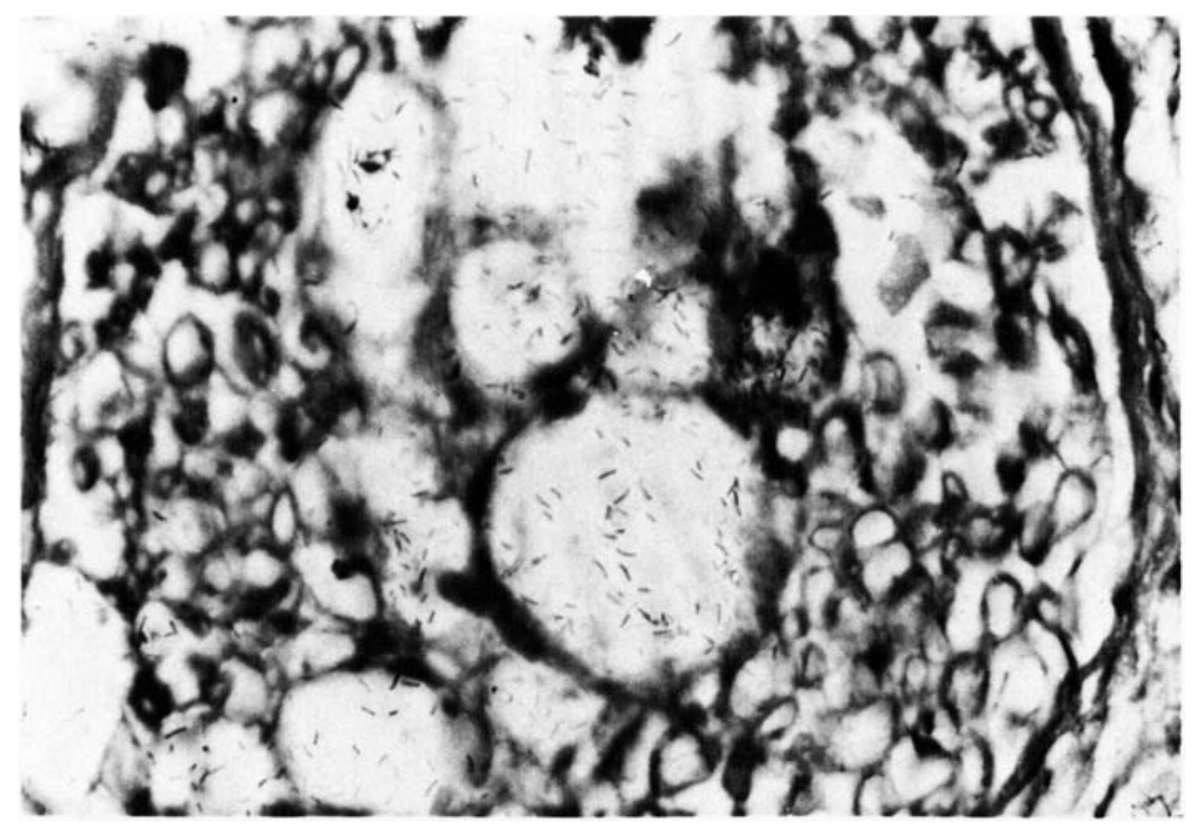

Fig. 10. The intraneural foam cells also contained numerous bacilli. Note the numerous normal axons around the foam cells. (A. F. $\times$ 1300.) 


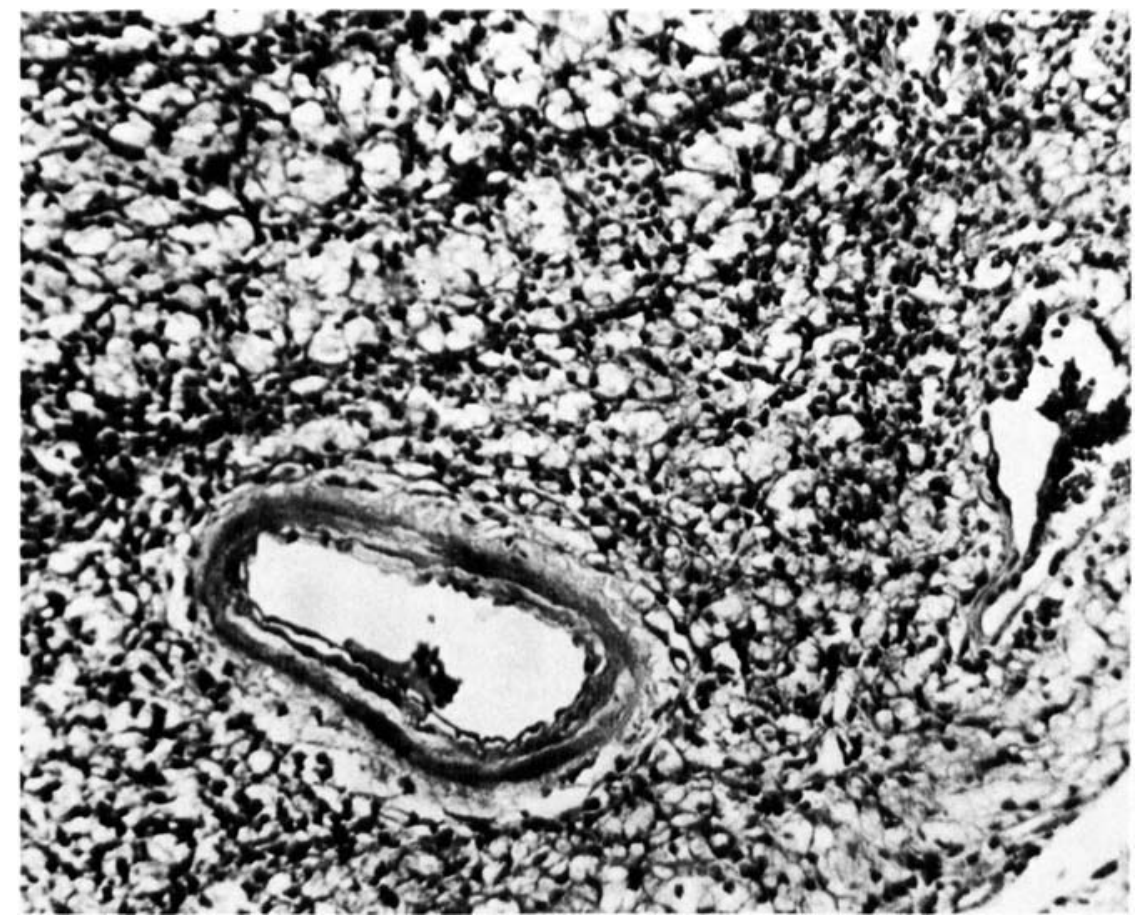

Fig. 11. In one mouse in focal areas of the leproma there were collections of lymphocytes infiltrating the foamy macrophages. (H \& E x 330.)

\section{Discussion}

The development of swelling and nodularity of the footpads of $\mathrm{T} 900 \mathrm{r}$ mice resembling human lepromatous leprosy seems to be an exception rather than the rule. Rees et al. (1968) refer in their paper to some animals among the many T 900r CBA mice they studied, which developed swelling of the footpads, and also describe in detail the histopathological picture in one. In most of the animals there was no obvious change at all in the infected foot. In our experiments conducted with T 900r mice using organisms obtained from 23 different patients with lepromatous leprosy this is the only strain of Myco. leprae in which nodularity of the feet of the animals was noticed. Six of the 17 animals available for study showed leproma of the feet. The procedure of thymectomy, irradiation and bone marrow replacement was exactly the same in all experimental animals, was done by one well trained technician, using the same equipment, and therefore less likely to have any appreciable variation. The CBA mice are being inbred in our own laboratory. Variability in their immunological status, though possible, is also not very likely. Further we have found this strain of Myco. leprae consistently giving rise to nodular swellings in 3 successive subcultures in $T 900 \mathrm{r}$ CBA mice. Therefore one might suggest that this particular strain of organisms proliferated more rapidly than the others. If that be the case, should it not produce nodular granulomatous swelling in all the 17 mice inoculated with this organism? Instead, only $6 / 17$ mice injected with this strain of the bacilli 
developed the swelling. Whether the swelling and nodularity of the feet and proliferation of the $10^{4}$ organisms to $10^{9}$ in a period of 10 to 12 months are due to a change in the immunological status of the experimented animals, or whether they are due to a variation in the nature of the organism used in the infection, is not clear, although judging from our experience in this study the latter is more likely.

The animals could not be followed up for a period longer than 12 months because most of them developed a tapeworm infestation and died soon after 12 months. Myco. leprae in small numbers were seen in Kupffer cells in liver and reticulo-endothelial cells of the spleen in animals sacrificed at the end of 10 and 12 months showing that dissemination of the bacilli through the blood stream of various internal organs occurred within 10 months after a local infection in a T 900r CBA mouse. However, granuloma formation in the internal organs was not observed. Therefore it is reasonable to infer that the dissemination of the organism in the blood stream could not have taken place much earlier.

The organisms were found in abundance in macrophages, and equally so in the muscle cells. We may state that this strain of $M y c o$. leprae would grow freely not only in macrophages but in striated muscle cells also. The bacillary invasion and proliferation of striated muscles of the feet of $\mathrm{T} 900 \mathrm{r}$ mice was far more than what was seen in our previous study using normal mice (Job, 1970). This finding is in agreement with the observation of Rees and Weddell in 1968. Many of the striated muscle cells in the feet of these animals were colonized by bacilli and were destroyed. It is very likely that if these animals survived for a longer period, paralysis of the foot due to destruction of muscle tissue could be observed.

Most of the cutaneous nerves examined did not show invasion by in flammatory cells in haematoxylin eosin section. The granuloma only surrounded the nerve bundles (Fig. 6). Intraneural bacilli were very scanty. Shepard (1968) did not find nerve invasion in the early months of $M y c 0$. leprae infection in T 900r mice. However, in one cutaneous nerve of a mouse foot there was infiltration of the nerve bundle by foamy macrophages (Fig. 7). Bacilli were present in large numbers in intraneural macrophages (Fig. 10) as seen in nerves of lepromatous leprosy patients. It is interesting to point out that the nerve invasion was seen as early as 10 months after inoculation of Myco. leprae.

The lepromatous tissue in all animals had infiltrated bone and bone marrow (Fig. 8). Bone trabeculae also had been destroyed. These lesions are well known in small bones of the fingers in lepromatous leprosy patients (Job, 1963). Further, the lesion in the mouse skin showed flattened epithelium and a band of foamy macrophages containing Myco. leprae separated by a clear area from epithelium (Fig. 3). Cutaneous nerves were surrounded by bacilliferous macrophages (Fig. 6). All these resembled exactly the skin lesions of human lepromatous leprosy.

If lepromatous granuloma such as described here could be produced consistently in most of the T 900r mice in all experiments within 8 to 10 months, we would have here a good animal model to study lepromatous leprosy. But since it is a rare phenomenon its use is limited. However, we intend to study this particular strain of $M y c o$. leprae further and will report later on any further developments in its pattern of behaviour.

\section{Acknowledgements}

I am deeply grateful to Mr Samuel Joseph for the devoted and careful technical work and to Mr J. Ramamurthy for secretarial assistance. The funds for this study were provided by The Leprosy Mission, London, and American Leprosy Mission Inc., New York. 


\section{References}

(iaugas, J. M. (1967). liffect of X-irradiation and thymectomy on development of M. leprae infection in mice. Br. I. exp. Path. 48, 417-422.

Job, C. K. (1963). Pathology of leprous osteomyelitis. Int. J. I.epr. 31, 26-33.

Job, C. K. (1970). Bacteriology and pathological study of leprous lesions in the foot pads of mice. Ind. J. Path. Bact. 13, 109-111.

Job, C. K., Chacko, C. J. (i., Verghese, R. and Padam Singh, S: (1974). Enhanced growth of $M$. leprae in the foot pads of thymectomized irradiated mice. I.epr. India. Accepted for publication.

Levy, L., Murray, L. P. and Shepard, C. C. (1970). A comparative study of mouse foot pad inoculation of skin biopsy specimens from patients with lepromatous leprosy in San Francisco and Atlanta. Int. J. I.epr. 38, 54-59.

Rees, R. J. W. (1964). Limited multiplication of acid fast bacilli in the foot pads of mice inoculated with Mycobacterium leprae. Br. J. exp. Path. 45, 207-218.

Rees, R. J. W. (1966). Inhanced susceptibility of thymectomized and irradiated mice to infection with M. leprae. Nature, lond. 211, 657-658.

Rees, R. J. W., Waters, M. F. R., Weddell, A. G. M. and Palmer, F. (1967). Experimental lepromatous leprosy. Nature, Lond. 215, 599-602.

Rees, R. J. W. and Weddell, A. (;. M. (1968). Fxperimental models for studying leprosy. Ann. N.Y. Acad. Sci. 154, 214-236.

Rees, R. J. W. and Weddell, A. (;. M. (1970). Transmission of human leprosy to the mouse and its clinical implications. Trans. Roy. Soc. Med. Hyg. 64, 31-47.

Rees, R. J. W. (1971). The impact of experimental human leprosy in the mouse on leprosy research. Int. J. L.epr. 39, 201-215.

Shepard, C. C. (1960). The experimental disease that follows the injection of human leprosy bacilli into foot pads of mice. J. Exp. Med. 112, 445-454.

Shepard, C. C. and Congdon, C. C. (1968). Increased growth of $M$. leprae in thymectomized irradiated mice after foot pad inoculation. Int. J. Lepr. 36, 224-227. 